\title{
Leader-Member Exchange and Local/Expat Promotive and Prohibitive Voice Behaviors
}

\section{Ghulam Ali Arain, Zeeshan Bhatti \& Jonathan Crawshaw}

\begin{abstract}
Drawing on self consistency theory, this paper tests a new moderated-mediation model, where employees' supervisor based self-esteem (SBSE) is positively related to their promotive and prohibitive voice and mediates the positive relationship between leadermember exchange social comparison (LMXSC) and their promotive and prohibitive voice, but that these relationships are weakened for expatriate employees (compared to nationals) working in the Kingdom of Saudi Arabia (KSA). To test hypotheses, multi-source questionnaire data were collected from 341 matched supervisor-supervisee dyads working in a diverse range of companies in the KSA. As predicted, employees' SBSE is positively related to their promotive and prohibitive voice and mediates the positive relationships between their LMXSC and their promotive and prohibitive voice behaviors, but only for Saudi nationals. This study responds to recent calls for leadership and voice research that explores the potential moderating roles of macro environmental and contextual factors on employees' constructive voice behaviors.
\end{abstract}

Keywords: Leader-Member Exchange Social Comparison; Self Esteem; Voice; Expatriates; The Kingdom of Saudi Arabia 


\section{INTRODUCTION}

Individual employee voice, here defined as the voluntary, constructive, and often challenging, upward communication of work-related ideas and issues to management by employees, has been acknowledged as a significant predictor of the team and organizational effectiveness (LePine \& Van Dyne, 1998, 2001; Liang, Farh, \& Farh, 2012). In short, employee voice is a key source of the team and organizational learning and innovation, allowing firms to efficiently and effectively change, adapt and survive (Graham, 2002; Perlow \& Williams, 2003). Its absence, therefore, is viewed as a potential source of significant organizational failure and a threat to their sustained competitive advantage (e.g., Greenberg \& Edwards, 2009; Milliken, Morrison, \& Hewlin, 2003). Considering these proposed benefits, research has explored a wide range of employee dispositional, attitudinal, behavioral, and contextual factors that may motivate or inhibit their constructive voice behaviors in organizations (for reviews, see Morrison, 2014 and Chamberlin, Newton, \& Lepine, 2017).

Among behavioral antecedents of employee voice, the role of the line manager's leadership behavior has been of considerable interest. In particular, research has consistently reported that line managers' transformational (Detert \& Burris, 2007) or ethical (Walumbwa \& Schaubroeck, 2009) leadership behaviors, and/or leader-member exchange (LMX) quality (Wang, Gan, \& Wu, 2016) are important motivators for subordinates' constructive voice behavior. Conversely, line managers' negative leadership behaviors - such as abusive supervision (Ouyang, Lam, \& Wang, 2015; Xu, Loi, \& Lam, 2015) and narcissistic leadership (Carnevale, Huang, \& Harms, 2018) are considered to be significant inhibitors of subordinates' constructive voice. In exploring these findings further, a recent meta-analysis by Chamberlin et al. (2017) compares, via relative weights analysis, the effect sizes of such leadership behaviors on employees' promotive and prohibitive 
voice (Liang et al., 2012), and highlights LMX as the most influential motivator. Chamberlin et al. (2017), therefore, call for further research that seeks to examine and understand the relationships between employees' perceptions of LMX and their promotive and prohibitive voice. We respond to this call and seek to extend this established LMX-voice research, in a number of important ways.

First, we answer Chamberlin et al's (2017) call for more leadership and voice research that differentiates between the promotive and prohibitive forms of voice (see also, (Kakkar, Tangirala, Srivastava, \& Kamdar, 2016; Liang et al., 2012). Promotive voice refers to employees' suggestions and ideas to management that aim to improve future organizational performance. Prohibitive voice, alternatively, refers to employee feedback to management that aims to point-out past or ongoing problems that, if left unchecked, could harm the organization (Liang et al., 2012). While both are forms of constructive voice, promotive voice is positive in tone and therefore more easily interpreted (by managers and colleagues) as a positive behavior. Prohibitive voice, on the other hand, is more negative in tone and thus potentially more risky, should managers and peers view individuals as being overly critical or even disloyal (Liang et al., 2012). Importantly, recent empirical research has begun to confirm that promotive and prohibitive voice may be predicted by, and may predict, different constructs (Chamberlin et al., 2017). Thus, to extend this work, we explore the potential differential effects of LMX on both employees' promotive and prohibitive forms of constructive voice.

Second, we challenge the direct measure of LMX that has dominated the extant literature by focusing our attention on LMX social comparison (LMXSC), here defined as employees' comparisons between their own LMX quality and that of the coworkers' (Vidyarthi, Liden, Anand, Erdogan, \& Ghosh, 2010). LMX theory is based on the premise that leaders form relationships 
with their employees that are of varying quality (Dansereau, Graen, \& Haga, 1975). Despite this early emphasis on the importance of relationship variability, LMX research has tended to focus on the antecedents and outcomes of individuals' ratings of their own line manager's LMX quality. However, Vidyarthi et al. (2010), in focussing on LMXSC, found it to explain significant additional variance in employees' job performance and citizenship behaviors above and beyond the variance explained by LMX and other control variables. We extend this research, therefore, by examining the relationships between employees' LMXSCs and their promotive and prohibitive voice - two previously untested prosocial behaviors.

Third, we also answer recent calls for further research exploring potential mediators, and theoretical explanations, of the LMXSC - performance relationship (Martin, Guillaume, Thomas, Lee, \& Epitropaki, 2016; p. 68). To this end, we propose a new self-consistency theory (Korman, 1970) perspective, exploring the mediating role of employees' supervisor-based self-esteem (SBSE) in the relationship between their LMXSCs and their promotive and prohibitive voice. Employees' SBSE refers to a subordinate's self-evaluation of his/her worthiness resulting from the relationship with the supervisor (Landry \& Vandenberghe, 2009), and emerging research suggests this may be a particularly salient and powerful explanation of why LMX and LMXSC matter for employees' task and prosocial performance (Landry \& Vandenberghe, 2009).

Finally, our research focuses on the relatively under-explored Middle-Eastern work context of the Kingdom of Saudi Arabia (KSA). The KSA is the largest and the wealthiest country in the Middle-East and the biggest oil exporter in the world (Nurunnabi, 2017). The work relationships among employees in Saudi organizations are very complicated due to a mix of local Saudis and a significant expatriate workforce that make up one-third of the total KSA working population (Edgar, Azhar, \& Duncan, 2016). Importantly, research suggests that this expatriate workforce is 
considerably less privileged than their Saudi counterparts, with expatriates often having significantly reduced salaries (for the same work), bargaining power, job autonomy, job security, and rights to speak up against any supervisory abuse than their Saudi counterparts (Mellahi, 2007). We posit, therefore, that this labor-market context (i.e., locals versus expatriates) is likely to act as a boundary condition for the mediating effects of SBSE in the relationship between LMXSC and employee constructive - promotive and prohibitive - voice. More specifically, we expect that this mediation effect would be stronger for local Saudis than for expatriate employees, as expatriates would have fewer opportunities and expectations to engage in these types of constructive voice behaviors, irrespective of their perceived relationship with their supervisor. In exploring this potential moderator, we thus respond to Morrison's (2014) call for more research examining the effects of macro-level contextual factors on employees' (promotive and prohibitive) voice.

\section{RESEARCH CONTEXT: THE KSA}

The KSA is a member of the G20 and the largest exporter of oil and gas products, with almost $90 \%$ of its national revenue generated from oil exports (Nurunnabi, 2017). During the oil boom period of the 1970's, the Saudi economy experienced an exponential growth in economic and financial activities, which created thousands of jobs in Saudi companies. Given that the Saudi workforce could not meet the industry's demand for skilled workers, the Saudi government issued work visas to a large number of expatriates from all over the world, who now make up one-third of their total skilled workforce (Edgar et al., 2016). However, in the last two decades, the Saudi government has taken steps to replace some of these professional and skilled expatriate workers with newly educated and trained Saudis, not least through their Saudization program (Al-Asfour \& Khan, 2014; Nurunnabi, 2017). 
Although the Saudization program was initiated in the 1970s, it was given more attention during the 1990s, as Saudi-national unemployment rose rapidly. To further complement this program, in 2011, the Saudi government introduced another program named Nitaqat ("bands" or "zones"), which is a quota-based system that demands all companies to have at least $30 \%$ of their workforce made up of Saudi nationals (Koyame-Marsh, 2016). Failure to comply with the Nitaqat program may result in several punitive consequences, such as denial of new work visas and nonrenewal of existing visas for expatriates, hefty fines, and restriction of business activities for the firm. In continuation of these initiatives, the National Transformation Program 2020 and the recently introduced Saudi Vision 2030 have stressed the importance of Saudization by banning specific industries from hiring any more expatriates as well asking them to replace any existing expatriates with local Saudis.

Thus, due to (1) a large number of expatriate workers from a wide range of diverse sociocultural background and (2) the strict compliance of organizations to various Saudization programs, the working relationship in Saudi companies has become complicated. On the one hand, employers prefer to hire expatriate workers, who in comparison with local Saudi workers, are cheaper, easier to control (e.g., expatriates cannot change their jobs without the consent of their employer or sponsor, named Kafeel), less demanding, and perceived as more hardworking than local Saudis (Longva, 1999; Mellahi, 2007). On the other, National policy increasingly compels employers to hire more local Saudis, which has created a climate of fear and career risks for many expatriates. We propose, therefore, that this complex labor market and work climate provide an interesting context to explore the potential differential relationships between LMXCS, SBSE and employees' voice behaviors for local Saudi and expatriate workers (Chamberlin et al., 2017; Morrison, 2014; Morrison \& Rothman, 2009). We thus extend prior research by exploring the 
implications of LMXCS for employees attitudes (SBSE) and behaviors (promotive and prohibitive voice) within a complex local-expatriate labor market context in the KSA.

\section{THEORETICAL FOUNDATIONS AND LITERATURE REVIEW}

\section{Employee Constructive Voice}

While early studies defined voice as an employee's 'self-oriented' reaction to unsatisfying work conditions (Rusbult, Farrell, Rogers, \& Mainous, 1988; Withey \& Cooper, 1989), later work has tended to focus attention on employee's 'other-oriented' discretionary and prosocial voice behavior targeted at improving team and organizational effectiveness (LePine \& Van Dyne, 1998; Van Dyne, Cummings, \& Parks, 1995; Van Dyne \& LePine, 1998). As such, Van Dyne and LePine (1998) define voice in terms of employees, "making innovative suggestions for change and recommending modifications to standard procedures" (p. 109). Extending this definition, Liang et al. (2012) categorized employee voice into its promotive and prohibitive forms. Promotive voice refers to an employee's upward sharing of positive and creative suggestions to management in order to enhance organizational effectiveness. Prohibitive voice, on the other hand, refers to their upward challenging of perceived counter-productive or harmful organizational, team, and individual norms, practices, attitudes and/or behaviors (Liang et al., 2012).

Early research that treated voice as a unidimensional construct confirmed its salience in predicting an array of workplace outcomes, such as managerial effectiveness, (Morrison, 2011), team innovation and safety (Li, Liao, Tangirala, \& Firth, 2017), team learning (Edmondson, 2003), in-role performance (Thomas \& Feldman, 2012), overall performance (Maynes \& Podsakoff, 2014), and, through the absence of voice, organizational failure (Greenberg \& Edwards, 2009; Milliken et al., 2003). More recent studies that treat promotive and prohibitive voice independently 
have begun to confirm their potential unique effects. For example, Li et al. (2017) report that while promotive voice may be a more important predictor of team productivity, prohibitive voice was more important for team safety.

Although both promotive and prohibitive forms of voice are the forms of a constructive voice that challenge the status-quo and benefits the collective (Liang et al., 2012), the way they do this is different. Promotive voice is future-oriented and positive in tone, and thus, is likely to be recognized and interpreted by others, including a line manager, as positive behavior. Prohibitive voice, on the other hand, is past-oriented, raising concerns over harmful work-related issues that have affected (or could affect) the organizational badly, and is more negative in tone. It is less certain, therefore, that others, including supervisors, will always interpret these behaviors positively, due to the heightened potential for interpersonal conflict and negative emotions that may stem from these contributions (Liang et al., 2012).

In line with this conceptual distinction between promotive and prohibitive voice, a recent meta-analysis suggests that positive supervisor-subordinate relationships (i.e., supervisor/leader openness and ethical leadership) may have a stronger more positive effect on employees promotive rather than prohibitive voice (Chamberlin et al. (2017). Chamberlin et al. (2017) draw on regulatory focus theory to explain these differential effects, suggesting that ethical leadership and line manager openness are leader behaviors orientated towards engaging employees in more positive prosocial behaviors and not avoiding negative outcomes (see also, Elliot \& Thrash, 2010). As such, they are promotion, and not prevention, focused leader behaviors and should, therefore, be more important in fostering employees' promotive, rather than prohibitive, voice behaviors (see also, (Svendsen, Unterrainer, \& Jønsson, 2017). Our research seeks to extend this emerging body 
of work that explores the potential differential antecedents of employees promotive and prohibitive voice, by introducing employees' LMXSC as a new independent variable.

\section{Leader-member Exchange Social Comparisons}

While most leadership theories suggest that a leader influences followers' attitudes and behaviors through a collective and equal treatment toward all the followers (Northouse, 2012), LMX theory (Dansereau et al., 1975) suggests that a leader forms relationships of differing quality levels with his/her followers (Graen \& Uhl-Bien, 1995; Liden \& Graen, 1980). According to Liden and Graen (1980), leaders' differing low-quality or high-quality relationships with followers motivate their followers to engage in social comparisons with each other to know their precise relative standing with their line manager. However, despite this early focus on the social comparison component of LMX, the vast majority of subsequent LMX research, including those studies exploring the outcomes of LMX, tended to focus on individual perceptions of LMX quality (for review on individual-level LMX-performance relationship (see the meta-analysis of Martin et al., 2016). According to Henderson, Wayne, Shore, Bommer, and Tetrick (2008), "although individual-level perceptions of LMX quality are reflective of interpersonal social exchange behaviors and motives in the leader-member dyad, they do not capture how the social context arising through within-group LMX differentiation, and the social comparisons occurring in this context, further influence employee attitudes and behaviors" (p. 1208).

Thus, to capture this within-group LMX differentiation, Henderson et al. (2008) measured relative LMX (RLMX), or the degree of difference between one's own LMX and the LMXs of coworkers, and reported that RLMX was positively related to psychological contract fulfillment and subsequent OCBs, after controlling for the effects of individual-level LMX. Advancing this 
work, Vidyarthi et al. (2010) measured LMX social comparison (LMXSC), or the comparison between one's own LMX and the LMXs of coworkers, and reported that LMXSC explained around 9\% additional variance in job performance and OCBs than the variance explained by LMX and other control variables ${ }^{1}$. In further validating these findings, more recent research has also found a significant and positive effect of LMXSC on employee performance (Xiao, Ping, \& Le, 2015), OCB, and interpersonal citizenship behavior (Arain, Afshan, Javed, \& Archimi, 2017; Kim, BAe, Lee, \& Kim, 2017).

In explaining the relationship between LMX and pro-social behavior, prior research has focussed attention on social exchange theory (Blau, 1964), which suggests that employee perceptions of LMX quality creates - in employees - a feeling of reciprocal obligation to balance the positive exchange with their leader through increased positive work behaviors (Cropanzano \& Mitchell, 2005). However, balancing the positive social exchange with the leader is not the only motivational mechanism through which LMX/LMXSC quality may translate into positive employee behaviors (Tse, Ashkanasy, \& Dasborough, 2012). Extant research has also drawn on role theory (Graen, 1976) and self-determination theory (Deci \& Ryan, 1985) when seeking to explain this relationship (see, Martin et al., 2016). Extending research, we turn our attention to self-consistency theory (Korman, 1970), and employees' supervisor-based self-esteem (SBSE), as an alternative - and underexplored - explanation of the relationship between LMXSC and employees' promotive and prohibitive voice.

\footnotetext{
${ }^{1}$ While, LMXSC and RLMX both are social comparisons based measures of with-group LMX differentiation, the former is a direct and subjective measure (i.e., one's self-evaluation of one's LMX as better than others within one's team), while the latter is an indirect and objective measure (i.e., one's LMX minus team mean LMX). Considering that LMXSC is a direct measure of one's subjective judgements of LMX differentiation Vidyarthi, P. R., Liden, R. C., Anand, S., Erdogan, B., \& Ghosh, S. 2010. Where do I stand? Examining the effects of leader-member exchange social comparison on employee work behaviors. Journal of Applied Psychology, 95(5): 849-861., it is likely to be a better predictor of individual level outcomes than RLMX Martin, R., Thomas, G., Legood, A., \& Dello Russo, S. 2018. Leader-member exchange (LMX) differentiation and work outcomes: conceptual clarification and critical review. Journal of Organizational Behavior, 39(2): 151-168.. As the outcomes of our study, i.e., LBSE and employee promotive and prohibitive voice, are at individual-level, we therefore, chose to use LMXSC for capture the effect of LMX differentiation on these outcomes. For more details on LMX differentiation measures, see Martin, R., Thomas, G., Legood, A., \& Dello Russo, S. 2018. Leader-member exchange (LMX) differentiation and work outcomes: conceptual clarification and critical review. Journal of Organizational Behavior, 39(2): 151-168..
} 


\section{LMXSC and SBSE}

Self-esteem, in its general form, refers to an individual's self-evaluation of their worth and competence (Rosenberg, 1965). Prior research suggests that self-esteem is a hierarchical and multifaceted phenomenon that can be built around any social, physical, and moral self, both at the individual and group level (Bowling, Eschleman, Wang, Kirkendall, \& Alarcon, 2010; Coopersmith, 1967; Pierce \& Gardner, 2004). As such, Pierce, Gardner, Cummings, and Dunham (1989) introduced the construct of organization-based self-esteem to refer to, "the degree to which an individual believes him/herself to be capable, significant, and worthy as an organizational member" (p. 25). In a meta-analytic study on the predictors and consequences of organizationbased self-esteem, Bowling et al. (2010) found that this specific form of self-esteem explained more variance in work attitudes and behaviors, including performance, than the general form of self-esteem.

While useful within an organizational context, the focus of organization-based self-esteem is still broad as it covers all aspects of one's organizational work-life (Landry \& Vandenberghe, 2009). Over time, therefore, organizational research has begun to identify more specific forms, or sources, of self-esteem. Given a supervisors' status and power within work units, increasing attention has been given to employees' potential to make evaluations of their self-worth based on this key agent and relationship (Lord \& Brown, 2001; Lord, Brown, \& Freiberg, 1999). Thus, in parallel to the notion of organization-based self-esteem, Landry \& Vandenberghe (2009) drew on self-consistency theory and conceptualized SBSE as employees' self-evaluations of their worthiness resulting from the relationship with their supervisor or line manager.

According to self-consistency theory (Korman, 1970), individuals derive their self-worth from their daily experience of social interactions with significant others at work. For most, the key 
agent or significant other in organizations is their line manager, given their direct and indirect influence - through the giving and withholding of resources, rewards, opportunities - over employees (Sguera, Bagozzi, Huy, Boss, \& Boss, 2017). Thus, given the salience of this relationship, when employees have a line manager who is encouraging, supportive, and treats them well, they tend to evaluate themselves as worthy of them. The limited extant SBSE-focused research has tended to support these proposals. For example, Sguera et al. (2017), across two studies (one a scenario study the other a three-wave field survey study), reported a significant and positive relationship between employees' perceptions of supervisory support and their SBSE. Moreover, Arain et al. (2017), in a survey of 298 manager-employee matched dyads working in 43 branches of a leading bank in Pakistan, suggest that employee perceptions of LMX quality have a significant and positive association with their leader-based self-esteem (i.e., SBSE). In line with self-consistency theory, therefore, we posit that employees' perceptions of high LMXSC - where they feel that they have a better relationship with their supervisor than most others in their workgroup (Vidyarthi et al., 2010) - is likely to result in them holding more positive SBSE. The following hypothesis is proposed:

Hypothesis 1. Employee perception of LMXSC is positively related to their SBSE

\section{SBSE and Employee Promotive and Prohibitive Voice}

Self-consistency theory also suggests that once positive self-esteem has become a part of an employee's self-concept, they, in turn, tend to "engage in and find satisfying those behavioral roles which maximize their sense of cognitive balance or consistency" (Korman, 1970; p. 32). In other words, the self-esteem literature suggests that employees with positive self-esteem - either organization based self-esteem (Pierce et al., 1989) or SBSE (Sguera et al., 2017) - tend to engage 
in those positive work behaviors which help them to be consistent with their positive self-esteem (Pierce \& Gardner, 2004). Bowling et al. (2010), in their meta-analysis, revealed that employee organization-based self-esteem had a positive association with a variety of positive employee work attitudes and behaviors including, their organizational commitment, job satisfaction, job involvement, OCBs and in-role performance, and had a negative association with negative outcomes such as, turnover intentions and depression. Building on self-consistency theory, a recent empirical study of Lin, Chen, Ashford, Lee, \& Qian (2018) also confirmed the positive effect of organization-based self-esteem on affective commitment and performance. Although based on a more limited body of research, employee SBSE has also been reported to have a positive association with positive employees work attitudes and behaviors such as, OCBs (Sguera et al., 2017) and in-role performance (Arain et al., 2017), and a negative association with negative behaviors such as, counterproductive work behaviors (Sguera et al., 2017).

Thus, building on self-consistency theory and these empirical findings, we suggest that employees SBSE will be positively related to their promotive and prohibitive voice behaviors and will explain the relationship between their perceptions of LMXSC and their promotive and prohibitive voice. Thus we argue that employees' belief that their supervisor trusts them and relies on them (high SBSE) (Landry \& Vandenberghe, 2009), motivates them to be consistent with that positive SBSE by voicing ideas and suggestions that may increase the efficiency and effectiveness of their team and supervisor (promotive voice) and by raising concerns over work-related issues that may harm the efficiency and effectiveness of their team and supervisor (prohibitive voice). Thus, we hypothesize the following relationships: 
Hypothesis 2. Employees' SBSE is positively related to their promotive voice and prohibitive voice and mediates the positive relationship between LMXSC and their promotive voice (H2a) and prohibitive voice $(\mathrm{H} 2 \mathrm{~b})$.

\section{Moderating Effect of Employee Nationality}

Morrison's (2014) review of the voice and silence literatures identified a number of potential inhibitors of employee constructive voice including, a climate of fear, perceived job futility, career risks, and high power distance. Many of these voice inhibitors are potentially pertinent to expatriate work life in Saudi organizations. For example, expatriates are not eligible for Saudi nationality, they cannot have their own businesses, and they even cannot change their jobs without the consent of their Saudi employer or sponsor (Longva, 1999). These contextual factors make expatriates powerless against the frequently reported abuse by their employers, for which limited or no protection is provided in the country's legal system (Mellahi, 2007). Additionally, the ongoing strict compliance with the Saudization programs has created a climate of job insecurity and uncertainty for many expatriates, with many reporting little hope in finding (alternative) work in other Saudi organizations (Mellahi, 2007)

Given that prior research suggests that employees' feelings of powerlessness and job/career insecurity may inhibit their constructive voice (Chamberlin et al., 2017; Morrison, 2014; Morrison \& Rothman, 2009), we expect that, despite perceiving high LMXSC and the resulted high SBSE that may stem from this positive interpersonal relationship, expatriates in the KSA would be less motivated to exhibit constructive voice than their Saudi counterparts as the wider labor market context and relationship with their Saudi employers mitigates against this rather risky prosocial activity. Indeed, prior empirical studies that compare employee voice among samples of locals and 
expatriates, consistently highlight that expatriate employees are less likely engaged in constructive voice than the local employees (Chen, Okumus, Hua, \& Nusair, 2011; Loi, Ao, \& Xu, 2014). Thus, considering that expatriates, particularly in the KSA, have lesser job security, benefits and career progression opportunities than their local counterparts, we expect that the mediation effect of SBSE in the relationship between LMXSC and promotive and prohibitive voice will be stronger for local Saudis than for expatriates. We hypothesize the following, therefore:

Hypothesis 3. Employees' SBSE is positively related to their promotive voice and prohibitive voice and mediates the positive relationship between LMXSC and their promotive voice (H3a) and prohibitive voice (H3b), but this is only significant for local Saudi nationals.

\section{INSERT FIGURE 1 ABOUT HERE}

\section{METHODS}

\section{Sample Characteristics}

Using convenience sampling and a supervisor-employee dyadic design, data were collected by distributing hard copies of two different questionnaires - one for a supervisor and one for his/her employee - at several domestic and multinational companies in KSA. Given our study sought to collect data from both Saudis and expatriates, the questionnaires were produced in both English and Arabic. The Arabic translation of our chosen measures - that were all originally validated in English - was made using the forward (from English to Arabic) and backward translation (from Arabic to English) method. The supervisor's questionnaire consisted of the measures of their employees' promotive and prohibitive voice. The employees' questionnaire consisted of the measures of LMXSC and SBSE. The two questionnaires were coded so that they could be later 'matched' and, we believe, they provide the most valid and reliable assessment of each variable, 
while also reducing the threat of common method variance and self-report biases (Podsakoff, MacKenzie, \& Podsakoff, 2012).

Business undergraduate students distributed 630 supervisor-supervisee questionnaires to several public and private organizations in the KSA. We first contacted and recruited employees who completed their questionnaire and named their supervisor. We then approached the named supervisors and asked them to complete a survey that rated their supervisee's promotive and prohibitive voice behaviors. Once both questionnaires were completed, we used the codes to pair them. It is worth noting that each supervisor rated only one employee. This reduced the burden on supervisors and allowed us to rule out the possibility of within-group difference in voice ratings for employees rated by the same supervisor.

After discarding 29 cases with mismatched dyads, and missing values, we collected 341 matched dyads giving an approximate 59\% response rate. Names of the respondents were erased during the data entry process to ensure anonymity. Among the participating supervisors, $69 \%$ were Saudis and 31\% were expatriates. Among Saudi supervisors, $76 \%$ were males, their average age was 37.51 years, and the average supervisor-supervisee relationship tenure was 3.13 years. Among expatriate supervisors, $80 \%$ were males, their average age was 37.22 years, and the average supervisor-supervisee relationship tenure was 3.03 years. Among the participating employees, $54 \%$ were Saudis. Among the Saudi respondents, $65.6 \%$ were males, the average age was 31 years, and the average experience was 4.57 years. Among the expatriate respondents, $77 \%$ were males, the average age was 33 years, and the average experience was 4.57 years.

\section{Measures}

Unless stated otherwise, all questions were measured on a Likert scale ranging from 1 (not at all) to 7 (a great extent). 
LMXSC was measured by using the 6-item scale developed by Vidyarthi et al. (2010). This scale measures employees' subjective judgment of the social comparisons of their LMX quality with the LMX quality of other members of their group/team. A sample item is: "The working relationship I have with my supervisor is more effective than the relationships most members of my group have with my supervisor". The alpha reliability value reported for this scale in this study is .94 .

SBSE was measured by using the 8-item scale developed by Landry and Vandenberghe (2009) and then further validated in a recent study of Sguera, Bagozzi, Huy, Boss, and Boss (2016). A sample item is: "My supervisor depends on me". The alpha reliability value reported for this scale in this study is 95 .

Promotive and prohibitive voice were measured by using the five-item scales for each developed by Liang et al. (2012). Sample items of promotive and prohibitive voice are, "He/she makes constructive suggestions to improve the unit's operation" and, "He/she advises other colleagues against undesirable behaviors that would hamper job performance" respectively. The alpha reliability value reported for promotive voice is .94 and for prohibitive voice is .94 .

Control variables. Supervisor age, gender, nationality (Saudi or expatriate), relationship tenure with the reported employee (i.e., since how long he/she has been supervising the reported employee), supervisee gender, age, nationality (Saudi or expatriate) and work experience were assessed due to their likely effect on employees' voice (Liang et al., 2012; Morrison, 2014; Van Dyne \& LePine, 1998). Additionally, employee promotion-prevention regulatory focus - the two strategic orientations that regulate an employee's cognition and behavior toward the achievement of positive outcomes and the avoidance of negative outcomes, respectively (Higgins, 1997) - have been reported as significant dispositional predictors of promotive and prohibitive voice (Lin \& 
Johnson, 2015), and were therefore collected using the scales developed by Lockwood, Jordan, and Kunda (2002).

\section{RESULTS}

\section{Confirmatory Factor Analysis (CFA)}

Before progressing to our main hypothesis testing, we carried out CFA on the main model variables to confirm their independence. We carried out this CFA using the structural equation modeling software AMOS version 23 (Arbuckle, 2014). In line with convention, we used a combination of fit indices - Comparative Fit Index (CFI), Tucker-Lewis Index (TLI), Standardized Root Mean Square Residual (SRMR) and Root Mean Square Error of Approximation (RMSEA) - to assess the adequacy of our model and compared our hypothesized model with a number of reasonable alternative measurement models (Bentler \& Bonett, 1980) CFI and TLI scores above .90 and SRMR and RMSEA scores below .70 are judged to confirm a good fitting model (Hair, Black, Babin, \& Anderson, 2010).

We tested four alternative models. Model 1 is our hypothesized 4-factor model comprising separate scales for LMXSC, SBSE, promotive voice, and prohibitive voice. Model 2 is a 3-factor model where promotive and prohibitive voice is combined into a single factor. Model 3 is an alternative 3-factor model where LMXSC and SBSE are combined into a single factor. Finally, Model 4 is a 1-factor solution where all items for all scales are loaded onto a single factor. Table 1 confirms that our hypothesized model $($ Model 1$)$ is an excellent fit of the data $(\mathrm{CFI}=.97, \mathrm{TLI}=$ .96, SRMR $=.04$, and RMSEA $=.06$ ) and all other alternative models provide a poor fit. Given these results, and the good Cronbach alpha reliability scores across all our measurement scales, we proceeded with the remainder of our analysis.

INSERT TABLE 1 ABOUT HERE 


\section{Descriptive Statistics}

All subsequent analysis was conducted using SPSS version 22 (IBM Corp., 2013) and the PROCESS macro version 2.16.3 (Hayes, 2012). Table 2 presents the means, standard deviations and inter-correlations of our model variables. As expected, our key independent and dependent variables correlate and in the predicted directions. For example, employees' perceptions of LMXSC are positively correlated with their SBSE $\left(r^{2}=.42, p<.01\right)$, promotive voice $\left(r^{2}=.18, p<.01\right)$ and prohibitive voice $\left(r^{2}=.25, p<.01\right)$. Moreover, employees' SBSE is positively correlated with their promotive voice $\left(r^{2}=.32, p<.01\right)$ and prohibitive voice $\left(r^{2}=.18, p<.01\right)$. As a result, we continued with our main model testing.

Table 2 also provides a summary of our potential control variables and their associations with our main dependent variables - SBSE, promotive voice, and prohibitive voice. It seems, in our sample at least, that only employees' age, supervisors' age, and employees' promotion focus are positively correlated with one or more of our dependent variables. Consequently, in order to test the most parsimonious model, we only controlled for these three variables in the remainder of our analysis.

\section{INSERT TABLE 2 HERE}

\section{Model Testing: Mediation Model (H1 and H2)}

To test hypotheses 1 and 2 we ran a PROCESS Model 4 (Hayes, 2012). Table 3 provides a summary of these findings. As predicted, employees' perceptions of LMXSC is positively related to their SBSE $(\mathrm{B}=.23, \mathrm{t}=7.21, \mathrm{p}<.001)$. It appears that as employees' comparative evaluations of their supervisor relationship improve so does their SBSE. Hypothesis 1 is therefore supported.

In turn, employees' $\mathrm{SBSE}$ is positively related to their promotive voice $(B=.37, \mathrm{t}=3.71$, $\mathrm{p}<.001$ ) and mediates the relationship between their perceptions of LMXSC and their promotive 
voice $(\gamma=.23,[.03, .15])$. Hypothesis $2 \mathrm{a}$ is thus supported. Against expectations, employees' SBSE is not significantly related to their prohibitive voice $(\mathrm{B}=.17, \mathrm{t}=1.27, n s)$ and consequently does not mediate the relationship between their perceptions of LMXSC and their prohibitive voice $(\gamma=.04$, $[-.02, .10])$. Hypothesis $2 b$ is rejected, therefore.

It appears that as employees' comparative evaluations of their supervisor relationship improve so does their willingness to engage in constructive feedback and suggestions to enhance organizational effectiveness (promotive voice) and, at least in part, this is explained by a greater SBSE. Conversely, however, while these positive LMXSC perceptions also have a similar - if not stronger - relationship with employees' engagement in more critical feedback to the organization about current failings and problems (prohibitive voice), this is not explained by their SBSE. While recent research suggests SBSE would be less strongly related to employees' prohibitive voice behaviors than their promotive voice behaviors, they still suggested a significant relationship (e.g., Chamberlin et al., 2017). Our findings suggest more significant differential effects of core selfevaluations like SBSE on employees' promotive and prohibitive voice behaviors.

INSERT TABLE 3 ABOUT HERE

\section{Model Testing: Moderated-Mediation Model (H3)}

To test hypothesis 3, we ran a PROCESS Model 14 (Hayes, 2012). Table 4 provides a summary of these findings. As predicted, the relationship between employees' SBSE and their promotive voice behaviors was only significant for local KSA employees $(\mathrm{B}=-.35, \mathrm{t}=-2.12, p<.05)$ (see also Figure 2). Moreover, the indirect relationship between employees' perceptions of LMXSC and their promotive voice, via their SBSE, was only significant for local KSA employees $(\gamma=-.08,[-.18,-.00])$ (see also Table 5). Hypothesis 3a was supported, therefore. Again, as 
predicted, the relationship between employees' SBSE and their prohibitive voice behaviors was only significant for local KSA employees $(\mathrm{B}=-.56, \mathrm{t}=-2.50, p<.05)$ (see also Figure 3 ). Moreover, the indirect relationship between employees' perceptions of LMXSC and their prohibitive voice, via their SBSE, was only significant for local KSA employees $(\gamma=-.13,[-.25,-.03])$ (see also Table 5). Hypothesis $3 \mathrm{~b}$ was also supported.

\section{INSERT FIGURE 2 ABOUT HERE INSERT FIGURE 3 ABOUT HERE}

\section{DISCUSSION}

Our research set out to test hypotheses derived from self-consistency theory (Korman, 1970). Specifically, we tested whether employees' SBSE mediated a positive relationship between their perceptions of LMXSC and their promotive and prohibitive voice, and whether these indirect relationships are the same for nationals and expatriates working in the KSA. Overall, we found very good support for our model. As predicted, employees' perceptions of LMXSC is positively related to their SBSE. It appears, in line with self-consistency theory, that positive line manager relations and, more importantly, the perception that one has a particularly good relationship with one's line manager compared with one's colleagues and their line managers, promotes in employees a self-belief that their line manager relies on them and that they are worthy of this attention (Landrey \& Vandenburghe, 2009).

In turn, we found that employees SBSE is positively related to their promotive voice behaviors, although we did not find a similar relationship with employees' prohibitive voice. It seems that SBSE is an important predictor of employees' voice behaviors associated with the 
communication of new and creative ideas to improve individual, team and organizational performance, but not voice behaviors associated with more critical feedback on negative individual, team, and organizational norms and practices that may be threatening the performance and survival of the firm. These differential effects of SBSE on promotive and prohibitive voice support recent propositions of Chamberlin et al. (2017) that suggest employee core self-evaluations would be a more important predictor of promotive rather than prohibitive voice. Chamberlin et al. (2017) argue that core self-evaluations, such as SBSE, help, "orientate employees towards the attainment of positive outcomes rather than the avoidance of negative outcomes" (p. 40) (see also Elliot \& Thrash, 2010). As such, core self-evaluations, such as SBSE, are more promotion focused and thus more likely to strongly influence more promotion-focused behaviors such as promotive voice (Chamberlin et al., 2017). Our findings support these propositions and the thus support the ongoing calls for more research that explores the differential antecedents of promotive and prohibitive voice.

Finally, as predicted, we found that the indirect relationship between employees LMXCS - SBSE - and both promotive and prohibitive voice was only significant for the Saudi nationals in our sample. For the expatriates, while their perceptions of LMXSC did have a positive effect on their SBSE, this did not translate into higher promotive or prohibitive voice behaviors. It appears, as predicted, that for this group, the wider work and labor market context may be inhibiting their desire and/or opportunities to provide voice in whatever form (Mellahi, 2007). Studies have shown that expatriate employees are less likely engaged in constructive voice than the local employees (Chen et al., 2011; Loi et al., 2014) and we argued that the Saudi context - one where expatriates work experiences and expectations may be affected negatively by ongoing national policy to promote more Saudis into key jobs and professions (Longva, 1999; Mellahi, 2007) - is likely to 
further inhibit this willingness to engage in voice behaviors, irrespective of their perceptions of the comparative quality of their line manager relationships. Put differently, quality interpersonal relationships with one's line manager cannot overcome - for expatriates - a work climate that is insecure, uncertain and (potentially) discriminatory and thus makes too risky, and inhibits, the enactment of both promotive and prohibitive voice.

\section{Theoretical and Empirical Contributions}

This study makes a number of important theoretical and empirical contributions to LMXSC and constructive voice literatures. First, we provide, to the best of our knowledge, the first empirical testing of the effects of LMXSC on promotive and prohibitive forms of constructive voice, extending leadership-constructive voice research in general and LMX-constructive voice research in particular. Drawing on early definitions and conceptualizations of LMX, we add to the growing body of work that is highlighting the importance of comparative LMX and its potential predictive influence over important employee attitudes and behaviors (Henderson et al., 2008). It seems that within-group differences in LMX ratings - in addition to actual LMX ratings - are a key antecedent of employees' voice and future research needs to keep recognizing this (Vidyarthi et al., 2010).

Second, we contribute to the growing voice literature that demands research tests for the differential effects of supervisor/leader behavior on promotive and prohibitive voice (Chamberlin et al., 2017; Svendsen et al., 2017). In line with Chamberlin et al. (2017), we found that LMXSC was positively related to both employees' promotive and prohibitive voice. However, counter to Chamberlin et al. (2017), it appears in our study that employees' LMXSC is more strongly related to their prohibitive rather than promotive voice. It appears, therefore, that prohibitive voice - in 
this context at least - is viewed as a similarly positively orientated behavior as promotive voice (perhaps even more so) and thus is as likely to be predicted by positive leadership behaviors such as LMXSC.

Finally, we extend research on the potential mediators and moderators of the LMXSC and constructive voice relationship. As expected, employees' SBSE mediated the relationship between employees LMXSC and both their promotive and prohibitive voice - but only for Saudi nationals. We thus, to the best of our knowledge, provide the first application of, and support for, a new selfconsistency theory (Korman, 1970) lens for understanding the relationships between employee's LMXSC and their voice behaviors. Given the specific context of our findings - that is, the rather complex KSA labour market - we call for much more research, in different national and industry contexts, that explores the role of employees' SBSE in the relationships between their LMXSC and voice, and thus tests the salience of self consistency theory as an alternative theoretical lens for understanding the implications of positive line manager-employee interpersonal relationships.

\section{Limitations and Future Research Directions}

Our findings must be interpreted in light of some methodological limitations. First, our model implies causal relationships between our core variables - specifically, that employees perceptions of LMXSC cause an effect on their SBSE that in turn causes an effect on the voice behaviors. One, however, could also imagine that an individual with a greater SBSE may subsequently rate their managers' LMXSC more highly. Moreover, one could imagine that an employee who is given opportunities to provide voice may rate more positively their relationship with their line manager. Our cross-sectional design does not allow us to effectively reject these alternative models and, despite our hypothesized model aligning with our theoretical framework 
and past LMX and LMXSC research (see, Martin et al., 2018), we therefore call for future longitudinal, diary-based, and/or experimental research that may be better able to test accurately these causal relationships.

Second, our research was carried out in the very specific KSA national context. This, of course, was deliberate and was done so in order to test specific hypotheses regarding the importance of LMXSC for both expatriate and national employees. However, the KSA is a particular context, and their national policies of Saudization may be fairly unique globally. Thus, our study may not be easily generalizable to other national contexts where large expatriate communities work side-by-side with nationals. The relative importance of employees' perceptions of LMXSC and SBSE for their voice behaviors in these alternative contexts is thus still unknown - although we hope that our research provides some new insight into these questions. As such, we again, call for more research, in new national contexts, that explores the (potential) differential effects of employees' LMXSC and SBSE on expatriate and national employees' voice behaviors.

\section{Practical Implications}

Despite these methodological limitations, our research delivers important practical benefits for organizations, in particular, multinational organizations that employ large numbers of expatriate workers alongside a national workforce. It seems, from our research at least, that while positive comparative line manager relationships are important for expatriate SBSE, this does not translate into expatriate voice behaviors. This is a significant problem. If multinational firms are to remain competitive, it is essential that they source ideas and feedback from all their employees and not just nationals (Graen \& Uhl-Bien, 1995) - whether this feedback is promotive or prohibitive in nature. Employee voice, and by turns silence, have been shown consistently to 
predict organizational learning, innovation, and performance and thus engendering the voice of all is a key objective of employers and their HR functions. Thus, organizations cannot simply rely on their line managers, and their effective development of strong interpersonal relations with their team members - in particular, their expatriate team members - to secure their voice engagement. It appears that the wider labor market and organizational context may matter as well. Expatriates need to feel secure in their jobs and valued by their organizations - and not just their line managers - if they are to engage in the essential voice behaviors organizations desire (Morrison, 2014; Morrison \& Rothman, 2009).

This said, for nationals (in this context), LMXSC is a potentially important predictor of employees' voice behaviors, and this is because positive LMXSC perceptions improve employees' SBSE. For organizations, therefore, it is important that their managers understand the importance of this key dyadic relationship and that employees' feel that they have a good relationship with their line manager in comparison to their peers. Managers may be made aware of this through any number of organizational communication channels - whether this is through company handbooks, memos and even formal training and leadership development programs. Importantly, they also need to monitor the quality of this essential relationship through their ongoing communications, annual performance reviews and other mechanisms such as annual staff surveys (Graen \& UhlBien, 1995). 


\section{REFERENCES}

Al-Asfour, A. \& Khan, S. A. 2014. Workforce localization in the Kingdom of Saudi Arabia: Issues and challenges. Human Resource Development International, 17(2): 243-253.

Arain, G. A., Afshan, G., Javed, U., \& Archimi, C. S. 2017. The Conditional Mediating Role of Leader-Based Self-esteem in the LMX-Performance Relationship, Academy of Management Proceedings, vol. 2017: 15864: Academy of Management.

Arbuckle, J. L. 2014. Amos (version 23.0) [Computer Program]. Chicago: IBM SPSS.

Bentler, P. M. \& Bonett, D. G. 1980. Significance tests and goodness of fit in the analysis of covariance structures. Psychological Bulletin, 88(3): 588-606.

Blau, P. M. 1964. Exchange and power in social life. New York: Wiley.

Bowling, N. A., Eschleman, K. J., Wang, Q., Kirkendall, C., \& Alarcon, G. 2010. A meta-analysis of the predictors and consequences of organization-based self-esteem. Journal of Occupational and Organizational Psychology, 83(3): 601-626.

Carnevale, J., Huang, L., \& Harms, P. 2018. Speaking up to the "emotional vampire": A conservation of resources perspective. Journal of Business Research, 91: 48-59.

Chamberlin, M., Newton, D. W., \& Lepine, J. A. 2017. A Meta-Analysis of Voice and Its Promotive and Prohibitive Forms: Identification of Key Associations, Distinctions, and Future Research Directions. Personnel Psychology, 70(1): 11-71.

Chen, P.-J., Okumus, F., Hua, N., \& Nusair, K. 2011. Developing effective communication strategies for the Spanish and Haitian-Creole-speaking workforce in hotel companies.

Worldwide Hospitality and Tourism Themes, 3(4): 335-353.

Coopersmith, S. 1967. The antecedents of self-esteem: Consulting Psychologists Pr.

Cropanzano, R. \& Mitchell, M. S. 2005. Social exchange theory: An interdisciplinary review. Journal of Management, 31(6): 874-900.

Dansereau, F., Graen, G., \& Haga, W. J. 1975. A vertical dyad linkage approach to leadership within formal organizations: A longitudinal investigation of the role making process. Organizational Behavior and Human Performance, 13(1): 46-78.

Deci, E. \& Ryan, R. 1985. Intrinsic motivation and self-determination in human behavior. New York, NY: Plenum.

Detert, J. R. \& Burris, E. R. 2007. Leadership behavior and employee voice: Is the door really open? Academy of Management Journal, 50(4): 869-884.

Edgar, D., Azhar, A., \& Duncan, P. 2016. The Impact of the Saudization Policy on Recruitment and Retention: A Case Study of the Banking Sector in Saudi Arabia. Journal of Business, 1(5): 01-14.

Edmondson, A. C. 2003. Speaking up in the operating room: How team leaders promote learning in interdisciplinary action teams. Journal of Management Studies, 40(6): 1419-1452.

Graen, G. B. 1976. Role-making processes within complex organizations. Handbook of industrial and organizational psychology, 1201: 1245.

Graen, G. B. \& Uhl-Bien, M. 1995. Relationship-based approach to leadership: development of leader-member exchange (LMX) theory of leadership over 25 years: applying a multi-level multi-domain perspective'. Leadership Quarterly, 6: 219-247.

Graham, G. L. 2002. If you want honesty, break some rules. Harvard Business Review, 80(4): 4247.

Greenberg, J. \& Edwards, M. S. 2009. Voice and silence in organizations: Emerald Group Publishing. 
Hair, J. F., Black, W. C., Babin, B. J., \& Anderson, R. E. 2010. Multivariate Data Analysis (7th ed.). Upper Saddle River: NJ: Prentice Hall.

Hayes, A. F. 2012. PROCESS: A versatile computational tool for observed variable mediation, moderation, and conditional process modeling: University of Kansas, KS.

Henderson, D. J., Wayne, S. J., Shore, L. M., Bommer, W. H., \& Tetrick, L. E. 2008. Leader-member exchange, differentiation, and psychological contract fulfillment: a multilevel examination. Journal of Applied Psychology, 93(6): 1208-1219.

Higgins, E. T. 1997. Beyond pleasure and pain. American Psychologist, 52(12): 1280-1300.

Kakkar, H., Tangirala, S., Srivastava, N. K., \& Kamdar, D. 2016. The dispositional antecedents of promotive and prohibitive voice. Journal of Applied Psychology, 101(9): 1342-1351.

Kim, H.-L. R., BAe, H., Lee, J. H., \& Kim, S. L. 2017. The Effect of Coworker LMXSC on Citizenship Behaviors: The Mediating Role of Coworker Exchange, Academy of Management Proceedings, vol. 2017: 12784: Academy of Management.

Korman, A. K. 1970. Toward an hypothesis of work behavior. Journal of Applied psychology, 54(1p1): 31-41.

Koyame-Marsh, R. O. 2016. Saudization and the Nitaqat programs: overview and performance. Journal of Accounting, 6(2): 36-48.

Landry, G. \& Vandenberghe, C. 2009. Role of commitment to the supervisor, leader-member exchange, and supervisor-based self-esteem in employee-supervisor conflicts. The Journal of Social Psychology, 149(1): 5-28.

LePine, J. A. \& Van Dyne, L. 1998. Predicting voice behavior in work groups. Journal of Applied Psychology, 83(6): 853-868.

LePine, J. A. \& Van Dyne, L. 2001. Voice and cooperative behavior as contrasting forms of contextual performance: evidence of differential relationships with big five personality characteristics and cognitive ability. Journal of Applied Psychology, 86(2): 326-336.

Li, A. N., Liao, H., Tangirala, S., \& Firth, B. M. 2017. The Content of the Message Matters: The Differential Effects of Promotive and Prohibitive Team Voice on Team Productivity and Safety Performance Gains. Journal of Applied Psychology, 102(8): 1259-1270.

Liang, J., Farh, C. I. C., \& Farh, J. L. 2012. Psychological Antecedents of Promotive and Prohibitive Voice: A Two-Wave Examination. Academy of Management Journal, 55(1): 71-92.

Liden, R. C. \& Graen, G. B. 1980. Generalizability of the vertical dyad linkage model of leadership. Academy of Management journal, 23(3): 451-465.

Lin, S.-H. J. \& Johnson, R. E. 2015. A suggestion to improve a day keeps your depletion away: Examining promotive and prohibitive voice behaviors within a regulatory focus and ego depletion framework. Journal of Applied Psychology, 100(5): 1381-1397.

Lin, X. S., Chen, Z. X., Ashford, S. J., Lee, C., \& Qian, J. 2018. A self-consistency motivation analysis of employee reactions to job insecurity: The roles of organization-based selfesteem and proactive personality. Journal of Business Research, 92: 168-178.

Lockwood, P., Jordan, C. H., \& Kunda, Z. 2002. Motivation by positive or negative role models: regulatory focus determines who will best inspire us. Journal of Personality and Social Psychology, 83(4): 854-864.

Loi, R., Ao, O. K., \& Xu, A. J. 2014. Perceived organizational support and coworker support as antecedents of foreign workers' voice and psychological stress. International Journal of Hospitality Management, 36: 23-30. 
Longva, A. N. 1999. Keeping migrant workers in check. Middle East Report, 29(2; ISSU 211): 20-22.

Lord, R. G., Brown, D. J., \& Freiberg, S. J. 1999. Understanding the dynamics of leadership: The role of follower self-concepts in the leader/follower relationship. Organizational Behavior and Human Decision Processes, 78(3): 167-203.

Lord, R. G. \& Brown, D. J. 2001. Leadership, values, and subordinate self-concepts. The Leadership Quarterly, 12(2): 133-152.

Martin, R., Guillaume, Y., Thomas, G., Lee, A., \& Epitropaki, O. 2016. Leader-Member exchange (LMX) and performance: A Meta-Analytic review. Personnel Psychology, 69(1): 67-121.

Martin, R., Thomas, G., Legood, A., \& Dello Russo, S. 2018. Leader-member exchange (LMX) differentiation and work outcomes: conceptual clarification and critical review. Journal of Organizational Behavior, 39(2): 151-168.

Maynes, T. D. \& Podsakoff, P. M. 2014. Speaking more broadly: an examination of the nature, antecedents, and consequences of an expanded set of employee voice behaviors. Journal of Applied Psychology, 99(1): 87-112.

Mellahi, K. 2007. The effect of regulations on HRM: private sector firms in Saudi Arabia. The International Journal of Human Resource Management, 18(1): 85-99.

Milliken, F. J., Morrison, E. W., \& Hewlin, P. F. 2003. An exploratory study of employee silence: Issues that employees don't communicate upward and why. Journal of Management Studies, 40(6): 1453-1476.

Morrison, E. W. \& Rothman, N. B. 2009. Silence and the dynamics of power. Voice and silence in organizations, 6: 111-134.

Morrison, E. W. 2011. Employee Voice Behavior: Integration and Directions for Future Research. The Academy of Management Annals, 5(1): 373-412.

Morrison, E. W. 2014. Employee voice and silence. Annual Review of Organizational Psychology and Organizational Behavior, 1(1): 173-197.

Northouse, P. G. 2012. Leadership: Theory and practice: Sage Publications.

Nurunnabi, M. 2017. Transformation from an Oil-based Economy to a Knowledge-based Economy in Saudi Arabia: the Direction of Saudi Vision 2030. Journal of the Knowledge Economy: 1-29.

Ouyang, K., Lam, W., \& Wang, W. 2015. Roles of gender and identification on abusive supervision and proactive behavior. Asia Pacific Journal of Management, 32(3): 671-691.

Perlow, L. \& Williams, S. 2003. Is silence killing your company? Ieee Engineering Management Review, 31(4): 18-23.

Pierce, J. L., Gardner, D. G., Cummings, L. L., \& Dunham, R. B. 1989. Organization-based selfesteem: Construct definition, measurement, and validation. Academy of Management journal, 32(3): 622-648.

Pierce, J. L. \& Gardner, D. G. 2004. Self-esteem within the work and organizational context: A review of the organization-based self-esteem literature. Journal of Management, 30(5): 591-622.

Podsakoff, P. M., MacKenzie, S. B., \& Podsakoff, N. P. 2012. Sources of method bias in social science research and recommendations on how to control it. Annual Review of Psychology, 63: 539-569.

Rosenberg, M. 1965. Society and the adolescent self-imagePrinceton University: Princeton. 
Rusbult, C. E., Farrell, D., Rogers, G., \& Mainous, A. G. 1988. Impact of exchange variables on exit, voice, loyalty, and neglect: An integrative model of responses to declining job satisfaction. Academy of Management Journal, 31(3): 599-627.

Sguera, F., Bagozzi, R. P., Huy, Q. N., Boss, R. W., \& Boss, D. S. 2016. The More You Care, the Worthier I Feel, the Better I Behave: How and When Supervisor Support Influences (Un) Ethical Employee Behavior. Journal of Business Ethics: 1-14.

Sguera, F., Bagozzi, R. P., Huy, Q. N., Boss, R. W., \& Boss, D. S. 2017. The More You Care, the Worthier I Feel, the Better I Behave: How and When Supervisor Support Influences (Un) Ethical Employee Behavior. Journal of Business Ethics: 1-14.

Svendsen, M., Unterrainer, C., \& Jønsson, T. F. 2017. The Effect of Transformational Leadership and Job Autonomy on Promotive and Prohibitive Voice: A Two-Wave Study. Journal of Leadership \& Organizational Studies: 1548051817750536.

Thomas, W. H. N. \& Feldman, D. C. 2012. Employee voice behavior: A meta-analytic test of the conservation of resources framework. Journal of Organizational Behavior, 33(2): 216234.

Tse, H. H. M., Ashkanasy, N. M., \& Dasborough, M. T. 2012. Relative leader-member exchange, negative affectivity and social identification: A moderated-mediation examination. The Leadership Quarterly, 23(3): 354-366.

Van Dyne, L., Cummings, L., \& Parks, J. M. 1995. Extra-role behaviors: In pursuit of construct and definitional clarity (a bridge over muddied waters). Research in Organizational Behavior, 17: 215-285.

Van Dyne, L. \& LePine, J. A. 1998. Helping and voice extra-role behaviors: Evidence of construct and predictive validity. Academy of Management Journal, 41(1): 108-119.

Vidyarthi, P. R., Liden, R. C., Anand, S., Erdogan, B., \& Ghosh, S. 2010. Where do I stand? Examining the effects of leader-member exchange social comparison on employee work behaviors. Journal of Applied Psychology, 95(5): 849-861.

Walumbwa, F. O. \& Schaubroeck, J. 2009. Leader personality traits and employee voice behavior: mediating roles of ethical leadership and work group psychological safety. Journal of Applied Psychology, 94(5): 1275-1286.

Wang, D., Gan, C., \& Wu, C. 2016. LMX and employee voice: A moderated mediation model of psychological empowerment and role clarity. Personnel Review, 45(3): 605-615.

Withey, M. J. \& Cooper, W. H. 1989. Predicting exit, voice, loyalty, and neglect. Administrative Science Quarterly: 521-539.

Xiao, Y., Ping, S., \& Le, T. 2015. Leader-Member Exchange Social Comparison, Perceived Insider Status and Employee's Job Performance: The Role of LMX Differentiation. Nankai Business Review, 4: 004.

Xu, A. J., Loi, R., \& Lam, L. W. 2015. The bad boss takes it all: How abusive supervision and leader-member exchange interact to influence employee silence. The Leadership Quarterly, 26(5): 763-774. 


\section{FIGURE 1}

\section{Hypothesized Model}

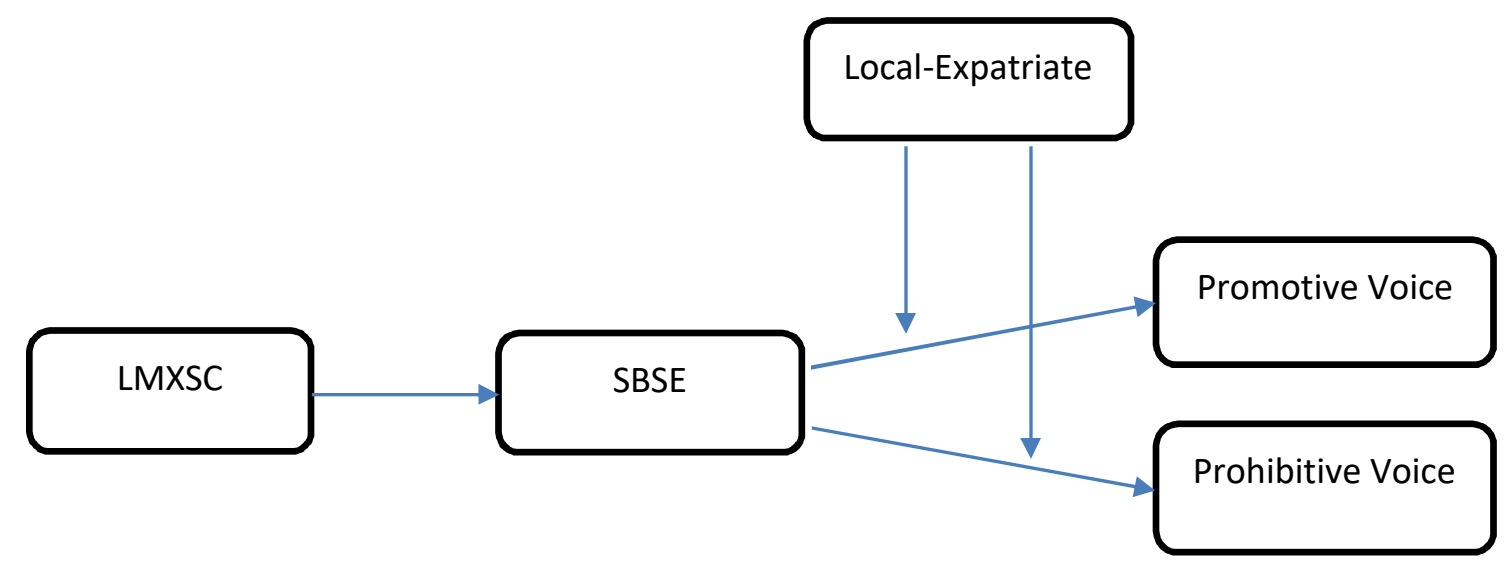


FIGURE 2

Plot of SBSE x Local-Expat Interaction Predicting Promotive Voice

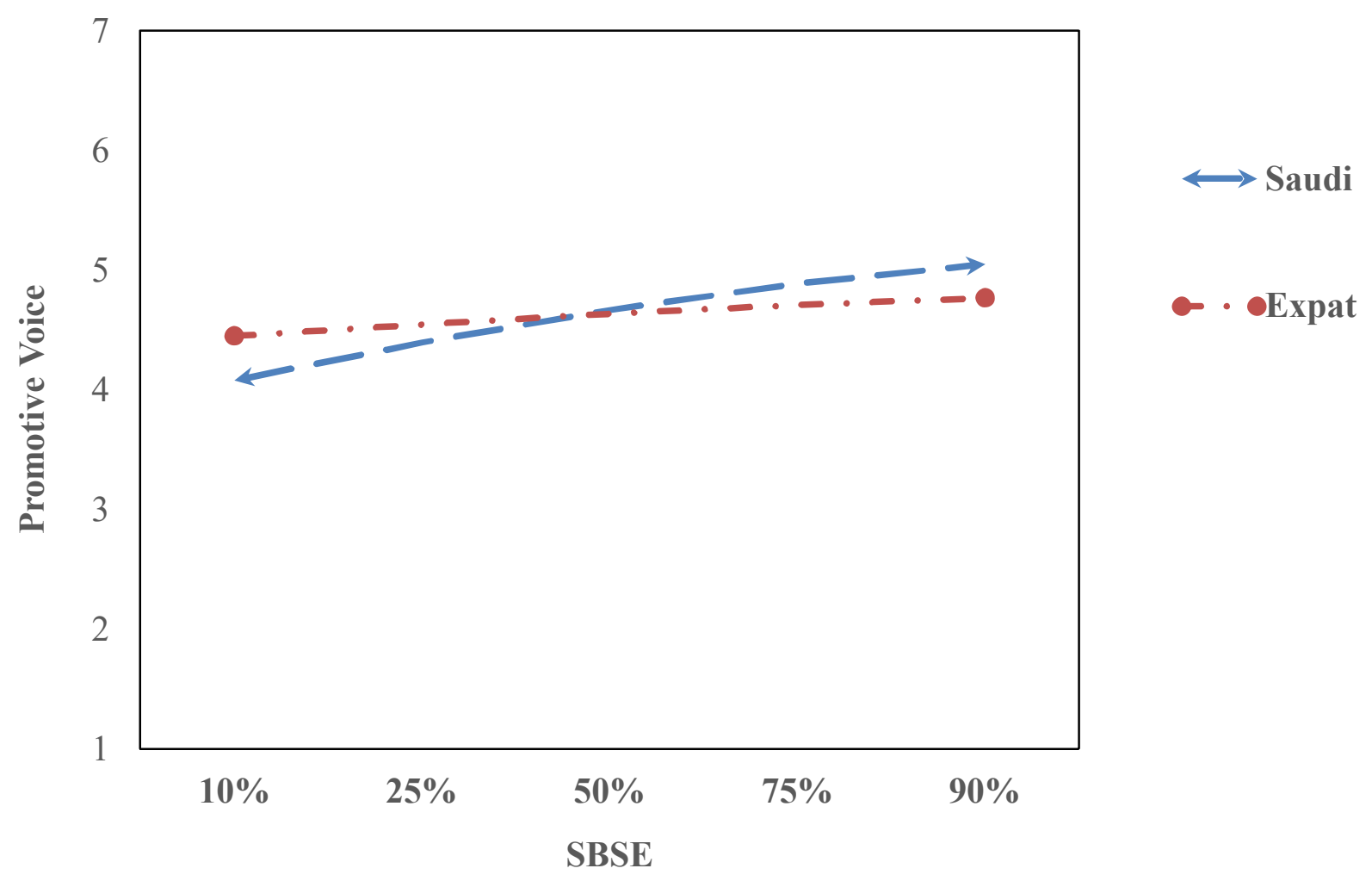


FIGURE 3

Plot of SBSE x Local-Expat Interaction Predicting Prohibitive Voice

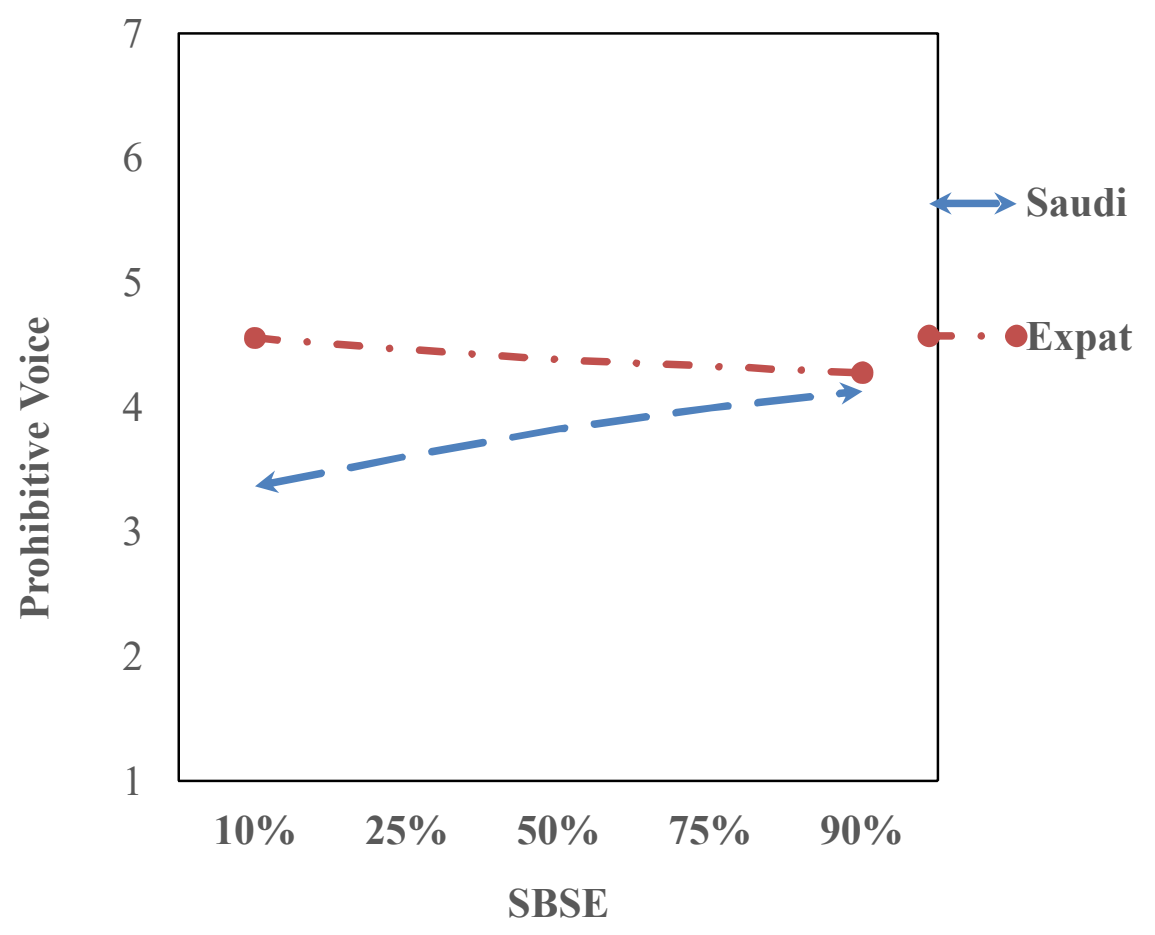


TABLE 1

CFA Model Fit Indices

\begin{tabular}{|c|c|c|c|c|c|}
\hline \multicolumn{2}{|c|}{ Measurement Model Comparison } & SRMR & CFI & TLI & RMSEA \\
\hline Model 1 & $\begin{array}{l}\text { 4-factor model: LMXSC, SBSE, promotive voice, } \\
\text { prohibitive voice }\end{array}$ & .04 & .97 & .96 & .06 \\
\hline Model 2 & $\begin{array}{l}\text { 3-factor model: promotive voice and prohibitive } \\
\text { voice merged. }\end{array}$ & .12 & .81 & .78 & .13 \\
\hline Model 3 & 3-factor model: LMXSC and SBSE merged. & .13 & .84 & .82 & .12 \\
\hline Model 4 & $\begin{array}{l}\text { 1-factor model: all measures loaded on a single latent } \\
\text { factor. }\end{array}$ & .22 & .50 & .45 & .21 \\
\hline
\end{tabular}

Note. $\mathrm{N}=341$; $\mathrm{SRMR}=$ Standardized Root Mean Square Residual; $\mathrm{CFI}$ = Comparative Fit Index;

TLI = Tucker Lewis Index; RMSEA = Root-Mean Square Error Approximation 
TABLE 2

Descriptive Statistics and Inter-Correlations

\begin{tabular}{lllllllll}
\hline Variables & Mean & SD & 1 & 2 & 3 & 4 & 5 & 6 \\
\hline 1. Employee Gender & - & - & & & & & & \\
2. Employee Age & 31.86 & 8.13 & $-.11^{*}$ & & & & & \\
3. Employee Tenure & 4.99 & 5.41 & $-.20^{* *}$ & $.74 * *$ & & & & \\
4. Supervisor Gender & - & - & $.55^{* *}$ & -.02 & -.07 & & & \\
5. Supervisor Age & 37.42 & 9.66 & $-.13^{*}$ & $.41^{* *}$ & $.32^{* *}$ & $-.15^{* *}$ & & \\
6. Relation Tenure & 3.10 & 2.92 & $-.17^{* *}$ & $.53^{* *}$ & $.61^{* *}$ & -.06 & $.51 * *$ & \\
7. Sup. Local-Expat & - & - & -.06 & -.03 & -.03 & -.05 & -.01 & -.02 \\
8. Prevention Focus & 3.92 & 1.49 & -.04 & -.05 & -.03 & -.06 & .04 & .01 \\
9. Promotion Focus & 5.28 & .71 & -.01 & .09 & .03 & .01 & $.13 *$ & -.01 \\
10. Emp. Local-Expat & - & - & $-.18 * *$ & $.12^{*}$ & .08 & -.02 & .06 & $.12 *$ \\
11. SBSE & 4.21 & .75 & -.03 & .07 & .06 & -.03 & .02 & -.01 \\
12. LMXSC & 3.58 & 1.08 & -.06 & .00 & .00 & .03 & .04 & .05 \\
13. Promotive Voice & 4.62 & 1.18 & -.03 & .09 & .03 & .02 & $.03 *$ & .02 \\
14. Prohibitive Voice & 4.08 & 1.58 & -.09 & $.12 *$ & .08 & -.02 & .03 & .07 \\
\hline
\end{tabular}

Notes. $\mathrm{N}=341 ;{ }^{*} p<.05,{ }^{*}{ }^{*}<.01 ;$ SBSE $=$ Supervisor-based Self Esteem; LMXSC = LeaderMember Exchange Social Comparison; Sup. = Supervisor; Emp. = Employee 
TABLE 2

Descriptive Statistics and Intercorrelations (Continued)

\begin{tabular}{llllllll}
\hline Variables & 7 & 8 & 9 & 10 & 11 & 12 & 13 \\
\hline 7. Sup. Local-Expat & & & & & & & \\
8. Prevention Focus & -.01 & & & & & & \\
& & & & & & & \\
9. Promotion Focus & .07 & .10 & & & & & \\
10. Emp. Local-Expat & $.37 * *$ & -.01 & -.03 & & & & \\
11. SBSE & -.04 & -.05 & $.48^{* *}$ & -.05 & & .05 \\
12. LMXSC & .04 & $.14^{* *}$ & $.23 * *$ & .04 & $.42^{* *}$ & & \\
13. Promotive Voice & .03 & .08 & .08 & .01 & $.32^{* *}$ & $.18^{* *}$ & \\
14. Prohibitive Voice & .08 & .07 & .07 & $.21 * *$ & $.18^{* *}$ & $.25^{* *}$ & $.39 * *$ \\
\hline
\end{tabular}

Notes. $\mathrm{N}=341 ;{ }^{*} p<.05,{ }^{*} p<.01 ; \mathrm{SBSE}=$ Supervisor-based Self Esteem; LMXSC $=$ Leader-

Member Exchange Social Comparison; Sup. = Supervisor; Emp. = Employee 
TABLE 3

Summary Regression Table of Mediation Model (H1 and H2)

\begin{tabular}{|c|c|c|c|c|c|c|}
\hline Model 1 & \multicolumn{6}{|c|}{ Supervisor-based Self Esteem (SBSE) (M) } \\
\hline IVs & $\mathrm{B}$ & $\mathrm{SE}$ & $\mathrm{t}$ & & & \\
\hline Constant & 1.27 & .29 & $4.30 * * *$ & & & \\
\hline Employee Age & .01 & .00 & 1.34 & & & \\
\hline Supervisor Age & -.01 & .00 & -1.41 & & & \\
\hline Promotion Focus & .43 & .05 & $8.82 * * *$ & & & \\
\hline Local-Expat & -.10 & .07 & -1.42 & & & \\
\hline $\operatorname{LMXSC}(\mathbf{X})$ & .23 & .03 & $7.21 * * *$ & & & \\
\hline Model 2 & \multicolumn{3}{|c|}{ Promotive Voice $(\mathbf{Y})$} & \multicolumn{3}{|c|}{ Prohibitive Voice (Y) } \\
\hline IVs & $\mathrm{B}$ & $\mathrm{SE}$ & $\mathrm{t}$ & $\mathrm{B}$ & $\mathrm{SE}$ & $\mathrm{t}$ \\
\hline Constant & 1.38 & .55 & $2.50^{*}$ & .48 & .74 & .65 \\
\hline Employee Age & .00 & .01 & .52 & .02 & .01 & 1.81 \\
\hline Supervisor Age & .01 & .01 & 1.31 & -.01 & .01 & -.76 \\
\hline Promotion Focus & .17 & .10 & 1.77 & .10 & .13 & .82 \\
\hline Local-Expat & .01 & .12 & .11 & .63 & .16 & $3.84 * * *$ \\
\hline $\operatorname{LMXSC}(\mathbf{X})$ & .08 & .06 & 1.26 & .29 & .08 & $3.44 * * *$ \\
\hline SBSE (M) & .37 & .10 & $3.71 * * *$ & .17 & .13 & 1.27 \\
\hline Indirect Effects & $\operatorname{Effect}(\gamma)$ & BootSE & [LLCI, ULCI] & $\operatorname{Effect}(\gamma)$ & BootSE & [LLCI, ULCI] \\
\hline SBSE & .08 & .03 & {$[.03, .15]$} & .04 & .03 & {$[-.02, .10]$} \\
\hline
\end{tabular}

Notes. $\mathrm{N}=341 ; * p<.05, * * p<.01, * * * p<.001 ;$ PROCESS Model $4 ; \mathrm{B}=$ Unstandardized Coefficients; LMXSC $=$ Leader-Member Exchange Social Comparison 
TABLE 4

Summary Regression Table of Moderated-Mediation Model (H3)

Model $1 \quad$ Supervisor-based Self Esteem (SBSE) (M)

\begin{tabular}{lrrc}
\hline IV & \multicolumn{1}{c}{$\mathrm{B}$} & $\mathrm{SE}$ & \multicolumn{1}{c}{$\mathrm{t}$} \\
\hline Constant & -3.06 & .28 & $-10.75^{* * *}$ \\
Employee Age & .01 & .00 & 1.19 \\
Supervisor Age & -.01 & .00 & -1.42 \\
Promotion Focus & .43 & .05 & $8.85^{* * *}$ \\
LMXSC (X) & .23 & .03 & $7.14 * * *$ \\
\hline
\end{tabular}

\begin{tabular}{lcccccc}
\hline Model 2 & \multicolumn{3}{c}{ Promotive Voice (Y) } & \multicolumn{3}{c}{ Prohibitive Voice (Y) } \\
\hline IV & $\mathrm{B}$ & $\mathrm{SE}$ & $\mathrm{t}$ & $\mathrm{B}$ & $\mathrm{SE}$ & $\mathrm{t}$ \\
\hline Constant & 3.07 & .60 & $5.12^{* * *}$ & 2.30 & .80 & $2.87^{* *}$ \\
Employee Age & .00 & .01 & .38 & .02 & .01 & 1.65 \\
Supervisor Age & .01 & .01 & 1.12 & -.01 & .01 & -.99 \\
Promotion Focus & .17 & .10 & 1.78 & .11 & .13 & .82 \\
LMXSC (X) & .07 & .06 & 1.08 & .27 & .08 & $3.24 * *$ \\
SBSE (M) & .36 & .10 & $3.63^{* * *}$ & .15 & .13 & 1.17 \\
Local-Expat (V) & .02 & .12 & .12 & .63 & .16 & $3.89^{* * *}$ \\
SBSE x Local-Expat & -.35 & .17 & $-2.12^{*}$ & -.56 & .22 & $-2.50^{*}$ \\
\hline Index of Mod-Med & Effect $(\gamma)$ & BootSE & {$[$ LLCI, ULCI] } & Effect $(\gamma)$ & BootSE & {$[L L C I$, ULCI] } \\
\hline SBSE & -.08 & .04 & {$[-.18,-.00]$} & -.13 & .05 & {$[-.25,-.03]$}
\end{tabular}

Notes. $\mathrm{N}=341 ; * p<.05, * * p<.01, * * * p<.001$; PROCESS Model 14; $\mathrm{B}=$ Unstandardized Coefficients; LMXSC $=$ Leader-Member Exchange Social Comparison 
TABLE 5

Conditional Indirect Effects of LMXSC on Promotive and Prohibitive Voice for Local and

\section{Expat Employees}

\begin{tabular}{llllll}
\hline \multicolumn{2}{l}{ Promotive Voice } & & & & \\
\hline Mediator & Employee & Indirect Effect & Boot SE & Boot LLCI & Boot ULCI \\
\hline SBSE & Local & .12 & .04 & .06 & .20 \\
SBSE & Expat & .04 & .03 & -.02 & .11 \\
\hline Prohibitive Voice & & & & \\
\hline Mediator & Employee & Indirect Effect & Boot SE & Boot LLCI & Boot ULCI \\
\hline SBSE & Local & .09 & .04 & .03 & .18 \\
SBSE & Expat & -.03 & .04 & -.13 & .05 \\
\hline
\end{tabular}

Notes. SBSE = Supervisor-based Self Esteem 